\title{
Volatile Volatility: Conceptual and Measurement Issues Related to Price Trends and Volatility
}

\author{
Eugenio Díaz-Bonilla
}

\section{$2.1 \quad$ Introduction}

It is obvious that prices are crucial variables (although certainly not the only ones) in making decisions pertaining to production and consumption. Producers and consumers are affected by both price levels and changes in price levels (variability or volatility). In the case of agricultural and food policies, there have been several debates about adequate price levels of food products and ways of reducing price volatility to a degree that does not interfere with the signaling effects of prices for economic decisions. Those policy issues revolve around balancing the interests of producers and consumers in increasingly differentiated societies in both industrialized and developing countries.

In the 1990s, policy debates focused on global price levels and whether they were too low. The last two price spikes in 2008 and 2011 have led to renewed concerns about the impacts of high food prices and shifted the focus back on food price volatility. The effects of changes in price trends on food production and food consumption (a discussion about price levels) are different from the effects of changes in volatility around those trends (cycles and extreme events), but both aspects are related. Policy analyses about those developments require clarifying some existing questions about both price levels and their variability (Díaz-Bonilla and Ron 2010), such as what to measure (including the appropriate time frame and currency) and how to measure (for instance, how to characterize trends given the

\footnotetext{
E. Díaz-Bonilla $(\triangle)$

International Food Policy Research Institute (IFPRI), Washington, DC, USA

e-mail: E.Diaz-Bonilla@cgiar.org
} 
existence of different detrending methods; see, for instance, Canova 1998, 1999). The next section reviews in general several topics related to the impacts of price trends and variability. Then, the main section, divided into separate subsections, discusses different issues related to what to measure and how to do it. The final section concludes this chapter.

\subsection{Price Levels and Price Variability}

Price levels affect producers' profits (and therefore their incentives to produce) and food costs to consumers (and consequently their purchasing decisions and economic access to food). Therefore, much of the debate regarding different policy approaches to agricultural production and food security revolves around a traditional policy dilemma (Timmer et al. 1983): high prices to support production or low prices to help consumption. High agricultural prices and food prices should normally lead to more future production, improving future physical availability, while making consumption more costly and reducing economic access. The reverse is true for low agricultural prices and food prices, which would worsen availability but improve economic access.

Therefore, in the short run, high food prices benefit producers (all things else being equal), while low food prices help consumers. But in the medium to long term, high food prices may positively affect even net food buyers if higher food prices generate dynamic economic processes that raise employment rates and/or wages (in both rural and urban areas) by amounts that more than compensate for the greater cost of food. Ivanic and Martin (2014) and Headey (2014) have discussed the different short-, medium-, and long-term impact of price changes. For example, higher agricultural and food prices may lead to increased investments from the private and public sector in agricultural production and in rural areas; this positively affects employment and wages. If, as argued in different studies, growth in agricultural (and food) production has a large and positive multiplier effect on the rest of the economy (Haggblade and Hazell 2010; Haggblade et al. 2007), and appears to be more effective in reducing poverty than growth in other sectors (Christiaensen et al. 2010; Eastwood and Lipton 2000), then higher agricultural and food prices do not generally pose a dilemma in policymaking because they lead to more employment opportunities and higher wages, particularly for lower-income producers and workers. There may also be some positive dynamic effects if a policy leads to investments in productivity, thereby reducing production costs and prices in the medium term, even though it increases food prices in the short term.

The opposite may also happen: farmers shielded by highly protective policies and pampered by subsidies may not need to invest to attain their desired profit levels; therefore, protection and subsidization may lead to fewer investments and lower productivity (see, for instance, Fan 2008; Mogues et al. 2012; Allcott et al. 2006). Also, higher agricultural and food prices may increase wages and production costs in other productive activities. Consequently their external and 
internal competitiveness may be affected, leading to an overall reduction in domestic production and employment (see Díaz-Bonilla 2015).

Both high prices and low prices result in supply and demand adjustments if markets operate normally and if price signals are transmitted properly to producers and consumers. Higher prices should eventually lead to higher production and lower consumption; both effects would push prices lower (and vice versa in the case of lower prices).

Those who take the perspective of poor producers prefer high food and agricultural prices, arguing that the agricultural sector's multiplier effect has important benefits for employment and poverty alleviation; a small subset of those analysts gravitate toward protection and price support through government policies. Those who take the perspective of poor consumers emphasize the importance of low food prices because of their positive effect on urban and rural poverty and malnutrition. They usually suggest lower levels of protection and consider the use of some types of consumption subsidies. But governments need to take into account the welfare of both producers and consumers when considering the short-term impacts as well as the medium- to long-term dynamic effects.

This policy dilemma has led to a variety of policies in developing countries, with very mixed results. A government might try to keep producer prices high and consumer prices low through subsidies and market interventions, but the developing countries that have tried such an approach usually find the policies unsustainable. This is mostly caused by fiscal costs, the distortions generated in production and trade when not using market prices, and the usually inequitable distribution of costs and benefits.

The debate about price volatility differs from the previous discussion on price levels.

It has been argued that price instability generates uncertainties about the true price level for producers and consumers, and therefore, production and consumption decisions may lead to suboptimal outcomes compared with those attained under more stable price conditions. For producers, price volatility may reduce investments and cause production to shift toward lower-risk, but also less productive, technologies (although World Bank 2005 estimated that these effects may not be significant). High and variable food inflation and price spikes affect consumers negatively because of reduced or uncertain access to food. This is particularly true for poor and vulnerable households, whose incomes do not adjust with inflation and which do not have assets to stabilize their consumption patterns.

There may also be negative macroeconomic impacts, such as balance of payment, public deficits, and declining total investment because of uncertainty all of which may also have second-round effects on poverty and food security (Timmer 1989). It is also important to consider the political impacts-an increase in food prices could lead to social unrest and riots. However, some have noted that high price shocks (spikes), which are only one form of (asymmetric) volatility, rather than volatility in general, seems to motivate political riots and unrest (see Barrett and Bellemare 2011). Persistent food inflation also tends to generate political problems, but in many cases, sustained inflation (in contrast with price shocks) is the result 
of macroeconomic difficulties that may not be related to developments in food markets. ${ }^{1}$

It is therefore crucial to define "stability" and "volatility," polar opposites of each other. In the context of monetary policies, the idea of price stability has usually been interpreted as inflation in the range of $0-2 \%$ per year. However, more recently, when evaluating policies to confront the effects of the 2007/2008 financial crisis, it has been suggested that price stability could be redefined as annual inflation that does not exceed $4 \%$ (Blanchard et al. 2010). A "stable" annual inflation of $2 \%$ means that the nominal price level is permanently increasing. For example, at $2 \%$ annual inflation, the price level will increase almost $50 \%$ in nominal terms in 20 years; at $4 \%$, the price level will more than double over the same period. In other words, stability in price levels and stability in the rate of change of those price levels (i.e., stability of inflation) are two different concepts.

In the case of food and agricultural prices, the notion of stability for producers refers mainly to price levels, while for consumers, the main problems are associated with high and persistent food inflation.

When considering stability of price levels, it is important to distinguish between the trend, potential changes in that trend because of the emergence of a new trend, and the variability or volatility around those trends. The last concept, in turn, may include both a reasonably smooth business cycle movement and shorter-term volatility surrounding the business cycle, which may or may not reach extreme values (such as in the case of price spikes or crashes). Smooth and predictable price movements that are part of the economic business cycle (as in the case of macroeconomic models of inflation that consider the gap between actual and potential GDP) may be more easily anticipated. Therefore, such variability may be incorporated ex ante into economic decisions. Further volatility, in excess of the trend and cyclical movements, tends to have shorter durations and may cause price shocks, leading to prices falling outside the range of trends or normal cycles, depending on the time horizon utilized. Those extreme price events may be defined by their frequency (e.g., those that only happen $10 \%$ of the time historically) or by their magnitude (those that drastically deviate from the trend, such as by multiples of the standard deviation). These extreme price events are usually unanticipated, and they tend to cause economic and political disruptions.

In summary, not all types of what is commonly called "volatility" are the same, or have the same effects on production and consumption decisions; therefore, it is necessary to differentiate between price trends, their potential changes, business cycle variability around those stable or changing trends, and shorter-term variability, particularly in the event of extremely high (spikes) or low (crashes) prices.

\footnotetext{
${ }^{1}$ Hazell et al. (2005) argue that a nontrivial part of domestic price variability in agricultural and food products is related to macroeconomic factors (see also Dorosh et al. 2009; Rashid and Lemma 2011 in the case of Ethiopia).
} 


\subsection{Different Measures and Concepts}

Before analyzing how to define trends and volatility, it is necessary to discuss several data and measurement issues related to the variables of interest (here, food prices), as discussed immediately.

\subsubsection{Prices in Real or Nominal Terms}

The first question is whether trends and volatility are analyzed in nominal prices or in real (also called constant or inflation-adjusted) prices. In the case of the latter, an appropriate deflator must be identified, such as the export unit value index (EUVI) for advanced economies, the US Consumer Price Index (CPI), or the US Producer Price Index (PPI).

Figure 2.1 shows the IMF index for food and beverages in nominal terms with two different deflators: the EUVI and the US CPI.

The behavior of the nominal food index is different from the two real food indices, while the last two indices also behaved differently.

The nominal variable shows a large increase in the early 1970 s, reaching a plateau that lasted until the early 2000s. Then the index experienced another sharp hike, which is more drastic than the increase in the early 1970s, possibly arriving at a new plateau. In the plateau lasting from the mid-1970s to the late 1990s, the nominal

Food Price Indices (in US dollars):

Nominal (right axis) and Real (left axis)

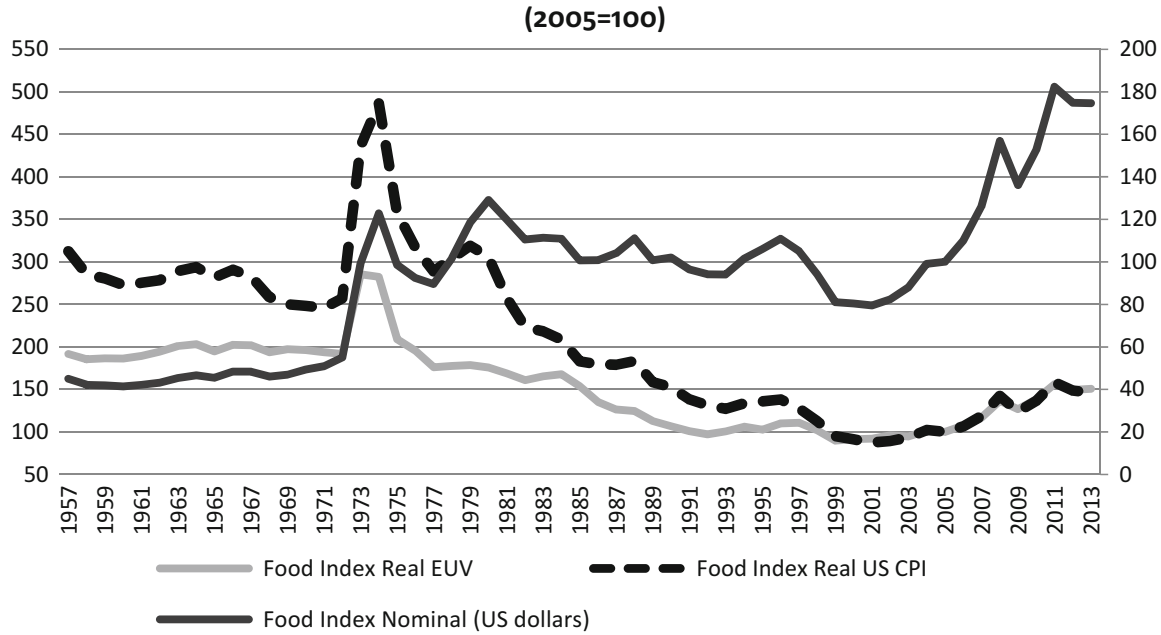

Fig. 2.1 Nominal and real food price indices. The IMF Food Price Index includes sub-categories for cereals, vegetable oils, meat, seafood, sugar, bananas and orange price indices Source: Author calculations based on data from the IMF 




Fig. 2.2 Trends in world growth and inflation of nominal food prices. Source: Author calculations based on data from the International Monetary Fund (IMF)

index showed a cyclical pattern and a relatively flat linear trend, with price peaks in 1974,1980 , and 1996. As the nominal index was climbing up to the second plateau, it peaked in 2008 and 2011.

The cyclical pattern during the plateau between 1980 and the mid-2000s appears to be influenced by, among other things, the global business cycle: When the world economy was growing faster, overall income and demand grew as well, and therefore, nominal prices went up. The opposite is true when there was slack in the global economy. This is a common pattern identified in the macroeconomic analysis of the business cycle and the behavior of variables such as wages and prices (see Rotemberg and Woodford 1999). Figure 2.2 shows the trends (using a HodrickPrescott filter) in world growth and food price increases.

The large increase in nominal prices in the first half of the 1970s was not exclusive to food products. Most commodities, including metals and energy, also experienced a nominal price upswing. This suggests that there was a common macroeconomic cause. In this case, the cause was related to the demise of the Bretton Woods monetary system of fixed exchange rates in the early 1970s, whereby the US dollar was strongly devalued against gold (see, for instance, Díaz-Bonilla 2010). In the 2000s, prices of metals and energy started rising in the earlier part of the decade, pushed by global growth and other macroeconomic factors; this was followed by the price increase of agricultural and food products, mostly happening in the second part of the decade (Díaz-Bonilla 2010).

The indices in constant 2005 prices, on the other hand, plateaued in the 1960s and 1970s, peaking once in 1973-1974 when deflated by the EUVI and twice when deflated by the US CPI (a larger peak in 1974 and a smaller one in 1979). Then both indices show a decline in real terms, but showing different patterns of decline. The 
Table 2.1 Price volatility in nominal and real terms

\begin{tabular}{l|c|c|c}
\hline Volatility & Nominal & Real EUVI & Real US CPI \\
\hline $1960 \mathrm{~s}$ & 3.4 & 2.8 & 3.9 \\
\hline $1970 \mathrm{~s}$ & 21.3 & 17.1 & 21.4 \\
\hline $1980 \mathrm{~s}$ & 6.7 & 5.0 & 7.0 \\
\hline $1990 \mathrm{~s}$ & 7.2 & 6.4 & 6.9 \\
\hline $2000 \mathrm{~s}$ & 9.9 & 6.4 & 9.1 \\
\hline $2010 \mathrm{~s}$ & 10.2 & 7.4 & 9.8
\end{tabular}

Source: Author calculations based on data from the International Monetary Fund (IMF). The period of 2010s includes 2010-2014

index deflated by the US CPI shows an earlier and steeper decline compared with the index deflated by the EUVI. Both indices show a trough in the late 1990s and early 2000s, and they have recovered moderately since then. The recovery, however, is clearly of smaller magnitude than the steep increase of the nominal index, and the indices have yet to reach the levels in the 1970s. Even the large peaks of the nominal indices in 2008 and 2011 appear far smaller when expressed in real prices (a discussion of the causes of those patterns can be found in Díaz-Bonilla 2010, 2015). Since 2011, all indices, both in nominal and real terms, appear to have reached a new plateau. A key question is what the future trends in nominal and real prices would be from 2015 onward (more on this below).

Moving the discussion from trends to price volatility, ${ }^{2}$ Table 2.1 shows a common measure of price volatility based on the standard deviation (SD) of a series constructed as $\ln p_{t}-\ln p_{t-1}$, where $t$ represents the time period (which may be days, months, years, and so on), $p_{t}$ refers to prices in levels, and $\ln$ is the natural logarithm (see, for instance, Gilbert and Morgan 2010; G20 2010). In this case, $t$ is defined as one year, and the table presents the average of the annual SD for each decade. It should be noted that $\ln p_{t}-\ln p_{t-1}$ is an approximation of the growth or changes in prices (which may be also called price "inflation" and could be negative) between two consecutive periods. Therefore, the measure utilized here reflects the volatility of annual price inflation.

All three variables show that volatility was low in the 1960s when exchange rates were stable; volatility became higher during the multiple shocks in the 1970s, and then it declined in the 1980s and 1990s (but remained higher than the levels in the 1960s). The measured volatility increased somewhat in the 2000s and the first half of the 2010s in the cases of nominal prices in US dollars and real prices when deflated by the US CPI. The index deflated by the EUVI showed no changes in the $2000 \mathrm{~s}$ and a small increase in the 2010s.

This section shows that it matters whether trends and volatility are expressed in nominal or real terms and which deflator is used.

\footnotetext{
${ }^{2}$ This measure can be applied to any variable and not only prices.
} 


\subsubsection{World Prices: In What Currency?}

As noted before, developments in world macroeconomic conditions need to be considered when analyzing price movements (see, for instance, Díaz-Bonilla 2010, 2015). In particular, exchange rate movements strongly influence nominal world food prices (as in the case of the breakdown of the Bretton Woods monetary system).

Figure 2.3 shows the inverse relationship between the US dollar (measured as the effective nominal exchange rate against major currencies) and the IMF nominal index of food products. ${ }^{3,4}$

The figure shows that the relative value of the US dollar fluctuated significantly, with peaks in the mid-1980s and the early 2000s, while the nominal food index moved in the opposite fashion. This implies that the currency used must be considered when analyzing food prices.

Figure 2.4 compares the evolution of nominal food indices in US dollar terms and special drawing rights (SDRs), a quasi-currency issued by the IMF. Being a basket of four major currencies (the euro, Japanese yen, pound sterling, and US dollar), it represents a more stable measure of value than the US dollar alone.



Fig. 2.3 Effective US exchange rate (nominal) (left axis) and nominal food price index (right axis). Source: Author calculations based on data from the International Monetary Fund (IMF) and the US Federal Reserve

\footnotetext{
${ }^{3}$ Mundell (2002), among others, pointed out the inverse relationship between the value of the US dollar and the price of commodities in that currency.

${ }^{4}$ The nominal food index is obtained from the IMF/IFS database. The US exchange rate is the index for major currencies in nominal terms calculated by the Federal Reserve. Major currencies include the euro, Canadian dollar, Japanese yen, British pound, Swiss franc, Australian dollar, and Swedish krona. There is also a broader index that considers more than 20 currencies (including the major currencies already mentioned). The indices can be calculated in nominal or in price-adjusted terms. The chart shows the same pattern if presented using the price-adjusted index for the broader set of currencies.
} 


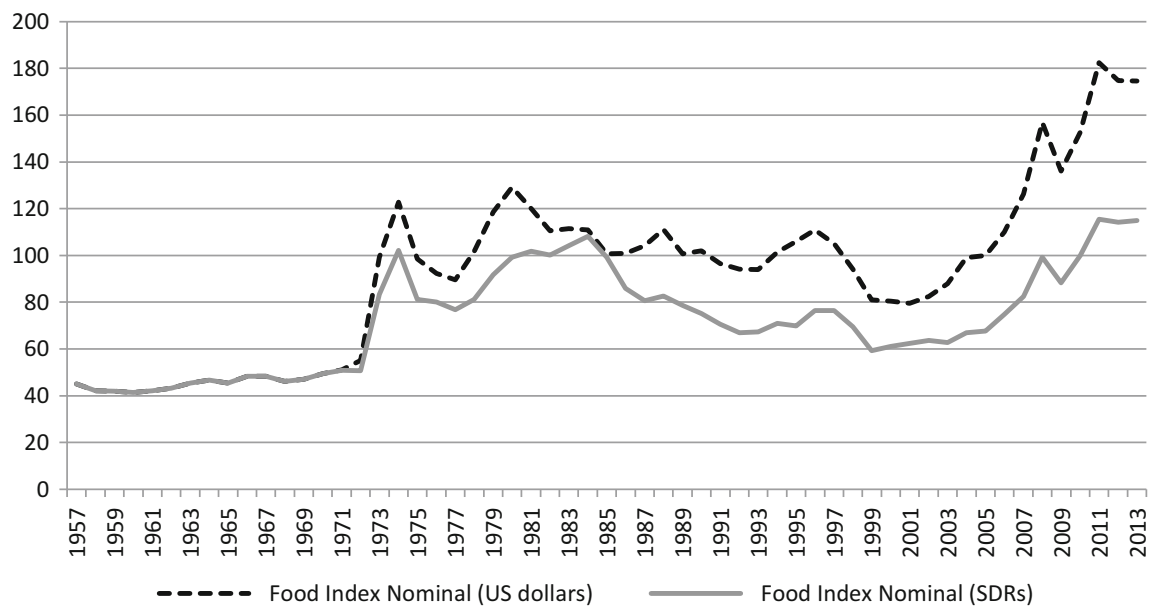

Fig. 2.4 Nominal food price indices in the US dollar and SDR $(2005=100$ for the US index). Source: Author calculations based on data from the International Monetary Fund (IMF)

Table 2.2 Price volatility in US dollars and SDRs

\begin{tabular}{l|c|c}
\hline Volatility & SDRs & USD \\
\hline $1960 \mathrm{~s}$ & 3.4 & 3.4 \\
\hline $1970 \mathrm{~s}$ & 18.8 & 21.3 \\
\hline $1980 \mathrm{~s}$ & 6.9 & 6.7 \\
\hline $1990 \mathrm{~s}$ & 7.1 & 7.2 \\
\hline $2000 \mathrm{~s}$ & 8.0 & 9.9 \\
\hline $2010 \mathrm{~s}$ & 8.0 & 10.2 \\
\hline
\end{tabular}

Source: Author calculations based on data from the International Monetary Fund (IMF). The period 2010s goes from 2010 to 2014

It is clear that the latest price surge, even in nominal terms, is less pronounced when calculated in SDRs. The 2008 price spike in SDRs was at or below the levels observed in the 1970s and 1980s, while nominal prices in the US dollar have been above historical averages during the latest price shocks, influenced by the depreciation of the US dollar from its peak in the early 2000s. Only after the price increase in 2011, the SDR index moved slightly above the values in the early 1980s.

Moving to the discussion of volatility, Table 2.2 shows the same measure of volatility as Table 2.1, comparing the nominal price indices in the US dollar and SDRs. Price volatility seems to be much less pronounced when prices are measured in SDR terms than in US dollar terms, suggesting that at least some food price volatility observed was influenced by additional instability in exchange rates, which is affected by general macroeconomic factors. 
The results above highlight the importance of taking into consideration the currency utilized in the pricing, which is affected by exchange rate fluctuations.

\subsubsection{Domestic Prices and World Prices}

In the earlier sections, the discussion focused on the different measures of world food prices. However, food security at national level is affected by domestic price volatility, which is correlated with world price volatility to different degrees in different countries. Price transmission from international to domestic prices can be limited because of several factors, such as domestic policies, high transportation costs, limited infrastructure, consumer preferences, and exchange rate variations.

Other sections of this book are devoted to the discussion of price transmission. It is important to note that as in the case of world prices, it is important to distinguish between nominal and real prices. The value chain level at which prices are measured also plays a role. Even if global food price changes are transmitted to the domestic economy (defined by some particular market level), their final effect on a consumer will be determined by the degree of integration between the local market in which the consumer participates and the national food market utilized as reference. In many developing countries in particular, there are clear distinctions between urban consumers, who may be more integrated with national markets, and rural consumers, who may have weaker links to national markets. Therefore, trends and volatility may differ when considering prices at the farm gate, wholesale, or consumer levels.

\subsubsection{Time Horizons}

The discussion of price volatility also requires the definition of a time horizon that is adequate for the purpose of the analysis. For instance, should data be analyzed daily, monthly, quarterly, annually, or at even longer intervals? Using annual values (as is the case so far) would obscure shorter term volatility: Daily, weekly, or monthly price movements may respond to several transitory causes that might cancel each other out during the course of the year. Still, these changes may be relevant for certain economic agents and their production and consumption decisions, therefore affecting their food security.

For instance, for consumers that are wage earners, the adequate interval may be a quarter or a month, in line with the timing of salary payments. For producers of annual crops, what matters may be the variability of the annual prices, while other producers, such as dairy farmers (who deliver daily), may be affected by shorterterm volatility. The level of development of futures markets and hedging instruments are also important when considering the appropriate frequency of analysis. In poor developing countries, daily and monthly price variability in futures markets does not drastically affect small-scale farmers' decision-making (with regard to crop production and marketing) because they do not have access to the futures markets. 
On the other hand, farmers in more developed countries may use futures market information to enter into different contracts and therefore find volatility information at daily or monthly intervals relevant for their business.

\subsubsection{The Selection of Food Indices and Food Prices}

The choice of food indices or food items is another aspect that deserves attention when analyzing food price volatility. This is because the final effect of food price volatility on food security at the national level will depend on the dietary preference of individual countries.

According to the food balance sheets calculated by the FAO (FAOSTAT 2014), Indonesia is a clear example of the importance of considering country-specific dietary preferences. Rice, a storable produce, accounts for (using 2009 data) around $48 \%$ of the calories and $40 \%$ of the proteins consumed on average (these values were $56 \%$ and $53 \%$, respectively, in 1980). The situation in India is somewhat more diversified than in Indonesia, with wheat and wheat products accounting for $21 \%$, and rice about $29 \%$, of the total calorie intake on average in 2009. On the other hand, many African countries show a consumption structure that shows a variety of products, including some (such as cassava and yams) that are difficult and costly to store. In 2009 in western Africa, ${ }^{5}$ the average calorie consumption comprises the following: $5.4 \%$ wheat and wheat products; $12.6 \%$ rice, $9.1 \%$ maize, and maize products; $10 \%$ millet and millet products; $9.1 \%$ sorghum and sorghum products; $8.7 \%$ cassava and cassava products; and $7.9 \%$ yams (see Díaz-Bonilla 2014).

The analysis of price movements may focus only on the most basic food staples (such as rice and wheat) as they represent an important portion of the dietary requirements in developing countries, and especially in the most vulnerable countries. However, as noted, some poor regions depend on several products for basic calories. Furthermore, access to a minimum level of food calories is insufficient to achieve food and nutrition security; dietary diversity also plays a role in nutrition security (Arimond and Ruel 2006). Therefore, to more comprehensively analyze the effects food price volatility, the price evolution of various food items should also be taken into consideration.

Also, if the analysis of price movements focuses on the impact of price volatility on general economic variables at the national level (in contrast to food security concerns), world food indices, such as those calculated by the IMF (used in this chapter), the World Bank, and the FAO, may not reflect the impact of price changes on a specific country because every individual index for those countries would

\footnotetext{
${ }^{5}$ Benin, Burkina Faso, Cabo Verde, Gambia, Ghana, Guinea, Guinea-Bissau, Liberia, Mali, Mauritania, Niger, Nigeria, Saint Helena, Ascension and Tristan da Cunha, Senegal, Sierra Leone, and Togo.
} 


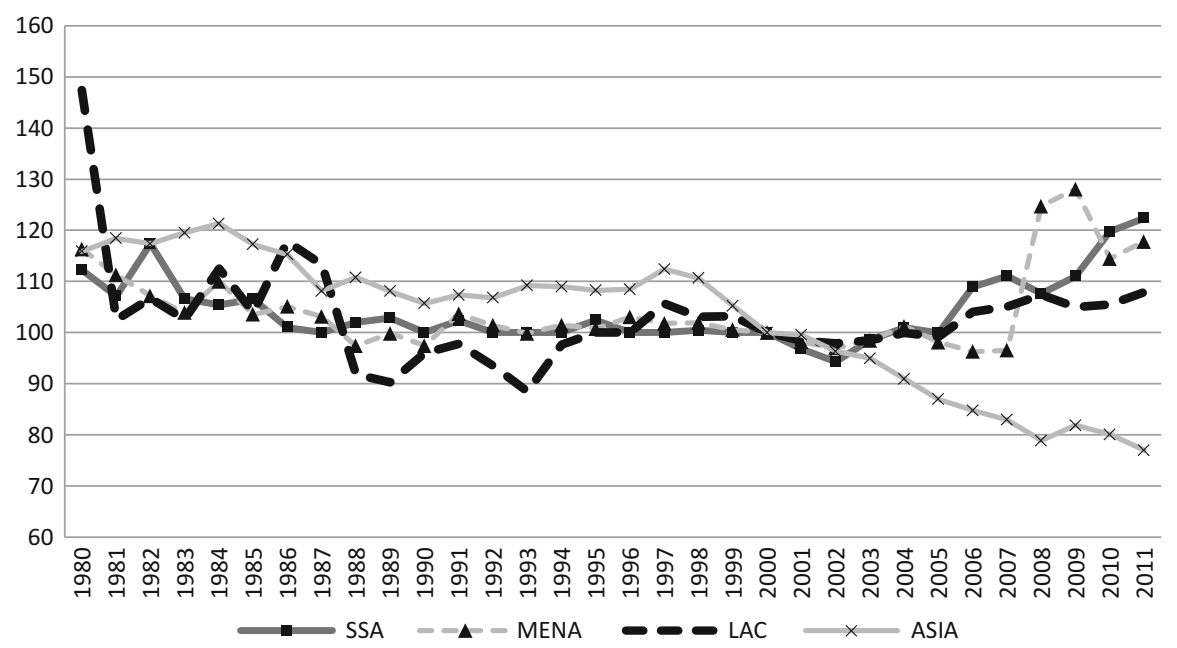

Fig. 2.5 Terms-of-trade index, median value $(2000=100), 1980-2011$. Source: Author's calculations based on World Bank (2014). Note: This corresponds to the median values for 36 countries for SSA, 17 for LAC, 6 for MENA, and 12 for Asia

have its specific basket of exports and imports. ${ }^{6}$ Figure 2.5 shows an indicator that better reflects that composition: the terms of trade for different developing regions, corresponding to the median values for 36 countries in sub-Saharan Africa (SSA), 17 in Latin America and the Caribbean (LAC), 6 in Middle East and North Africa (MENA), and 12 in Asia.

The terms of trade differ across regions, showing different responses even during the price spikes in 2008 and 2011. This indicates that the composition of exports and imports is different for every region. For instance, oil constitutes a great portion of export in MENA, and metals and oils have a strong presence in SSA; therefore, MENA and SSA saw a larger improvement in their terms of trade than LAC, which has a more diverse export basket. In MENA and SSA, higher food prices were more than compensated for by the price increase of other commodities, highlighting the importance of analyzing developments in all commodities at the same time and not focusing only on some of them. On the other hand, the developing countries in Asia, whose import structure relies more heavily on commodities, showed a decline in the terms of trade because the price of all commodities and not only food increased.

\footnotetext{
${ }^{6}$ The food price indices calculated by the IMF, the World Bank, and the FAO, although sharing broadly similar trends, are somewhat different in their coverage, in the weights they use to aggregate the prices of individual commodities, and in the representative world prices selected for some of them. Therefore, while the IMF index shows an increase in nominal prices of about $107 \%$ between 2003 and 2011, this figure is $121 \%$ for the World Bank and $135 \%$ in the case of the FAO. It would be useful if the international organizations could present a single index.
} 


\subsubsection{Trends and Volatility: Different Approaches}

As already mentioned, a common measure of volatility is the standard deviation of price changes (or inflation) within a specific period, which may be defined in days, months, years, and so on.

It was also noted that $\ln p_{t}-\ln p_{t-1}$ is a proxy for nominal inflation for the period $t$, which is defined as one year in Tables 2.1 and 2.2 (annual inflation). However, monthly inflation is often used (see, for instance, Gilbert and Morgan 2010; G20 2010, which use monthly price changes). It has been argued that using standard deviations of log prices is a better measure than other potential metrics because it avoids the issue of defining trends (see Gilbert and Morgan 2010).

In some instances, it may be enough to evaluate this measure of volatility. However, by not considering trends and changes in trends, key elements may be missed when analyzing relevant policy responses. In macroeconomics, a few studies have already noted that many crucial variables, such as GDP, seem to exhibit variable trends (see, for instance, Stock and Watson 1988, focusing on the US economy; Aguiar and Gopinath 2004, analyzing emerging markets). Also, the factors and policies affecting trends and changes in trends are usually different from those affecting the variability around the trends (although there may be cross effects).

If we accept the argument that both the variability of a trend and the variability around the trend need to be considered, then it is crucial to identify methods of decomposing price movements into trend variability (explained by long-term factors), variability around the trend (partially related to the business cycle), and shorter-term variability that lies beyond both trends and cycles (which may include extreme events such as spikes or crashes) (see Díaz-Bonilla and Ron 2010; Tadesse et al. 2014). The best methods of separating trends and cycles have been long debated in applied macro-econometrics, with different approaches leading to different results about such decomposition (see, for instance, Canova 1998, 1999, 2007).

In the following section, trends and cycles will be discussed firstly; then the issue of extreme events will be examined in further detail.

\subsubsection{Trends and cycles}

In relation to trends and cycles, three different detrending methods are used to demonstrate the different results that can be obtained from the methods. The three methods are as follows: the lineal trend (LT) (Fig. 2.6), the Hodrick-Prescott (HP) filter (Fig. 2.7), ${ }^{7}$ and the asymmetric Christiano-Fitzgerald (CF) filter (Fig. 2.8). ${ }^{8}$

\footnotetext{
${ }^{7}$ The HP filter is calculated with a lambda of 100 . Compared to the CF, the HP does not capture the turn at the end toward a plateau.

${ }^{8}$ The CF filter is the full sample asymmetric specification with the underlying variable considered to be non-stationary (as indicated by the tests on the nominal food price index) and cycle periods
} 
Food Price Index Nominal USD: LT Trend and Cycle



Fig. 2.6 Lineal trend

Food Price Index Nominal USD: HP Trend and Cycle

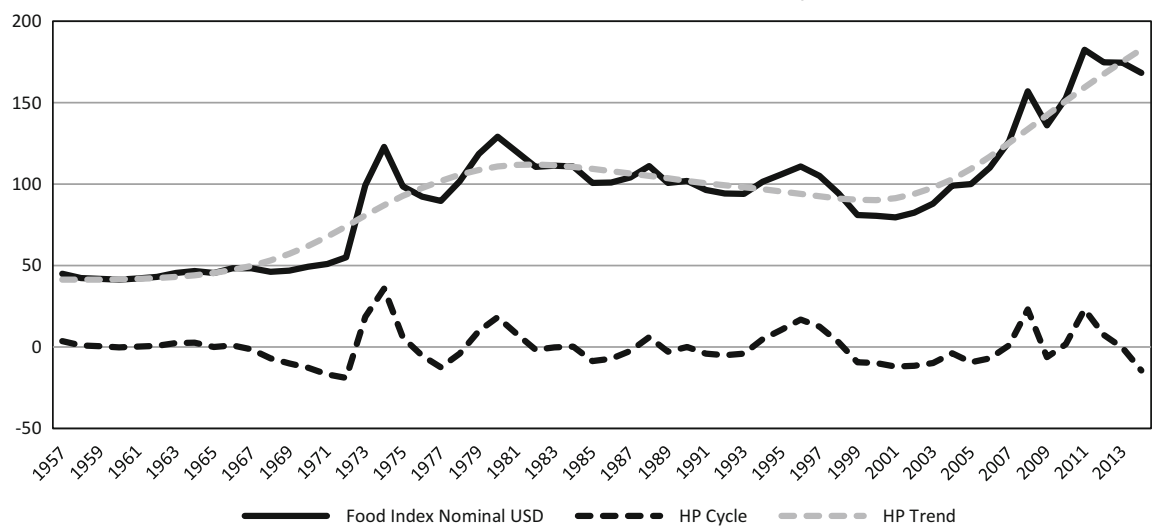

Fig. 2.7 Hodrick-Prescott filter. Source: Author calculations based on data from the International Monetary Fund (IMF)

The cycle in the respective figures is obtained by subtracting the value of the trend from the nominal value of $p_{t}$ at the same period $t$.

between 2 and 8 years. This specification allows the values at the beginning and end of the time series to remain in the calculations. In contrast, other band pass filters with fixed lags lose the values at the extreme ends of a time series because of the lags. As noted, the Hodrick-Prescott filter also has problems capturing the trends at the beginning and the end of a series. The advantages and limitations of the different filters, neither of which are perfect, are discussed in detail in Canova (2007). Canova (1998) also gave a more detailed comparison of different detrending methods using macroeconomic series. 
Food Price Index Nominal USD: CF Trend and Cycle

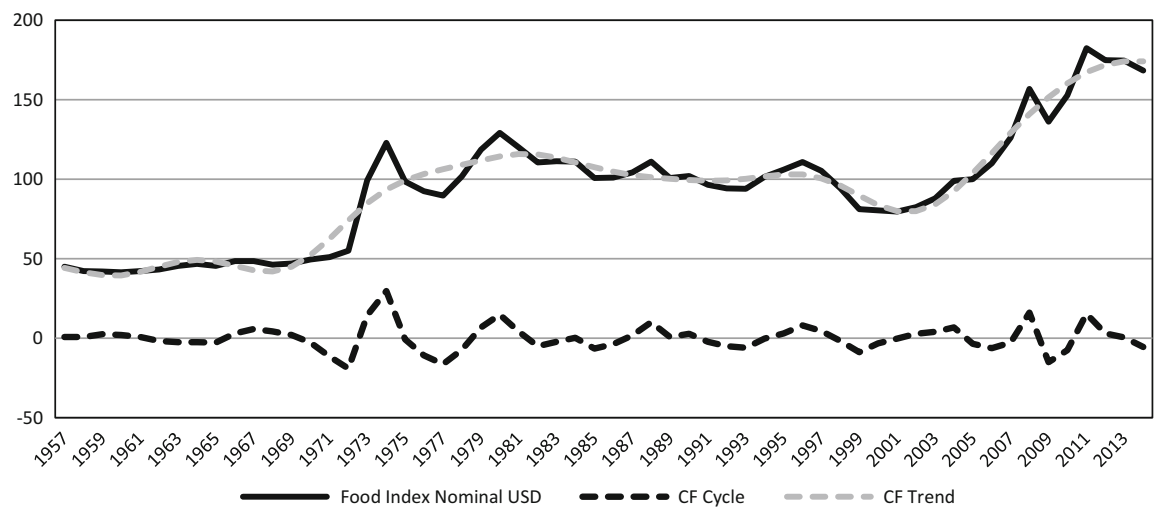

Fig. 2.8 Christiano-Fitzgerald filter. Source: Author calculations based on data from the International Monetary Fund (IMF)

Several observations can be made about the figures above: First, regardless of the method applied, the price volatility between the late 1950s and the first half of the 1970s was lower compared to the rest of the series. Second, the LT has the problem of being constant during the period considered, even though tests have shown ${ }^{9}$ that there were structural breaks in the trend. Both the HP and the CF were able to capture changes in trends, although they show slightly different results. There are no conclusive tests to determine which method captured the "correct" trend. Third, the HP, which usually has problems detecting changes at the end of a series, signals a continuation of the upward trend, while the $\mathrm{CF}$ is already pointing to an inflection point in the upward movement. Fourth, regardless of the method applied, the three detrending methods show larger increases in the mid-1970s than in the more recent price spikes. Finally, the CF filter considers the trough in the 1990s as a change in trend, while the LT and, to a lesser extent, the HP evaluated the period as a down cycle.

Table 2.3 presents a measure of volatility different from that shown in Tables 2.1 and 2.2. Here volatility is calculated as the decade average of the percentage deviation (in absolute values) of the food index from the trends calculated using LT, HP, and CF. ${ }^{10}$ For comparison, the table also includes the measure of volatility

\footnotetext{
${ }^{9} \mathrm{~A}$ simple test, not shown here, was conducted on the stability of the coefficient of a trend variable with the following equation: $y(t)=a+b \times y(t-1)+c \times$ lineal trend. $Y(t)$ is the nominal index for food prices, in both original value and $\log$ form. Tests on the coefficient $\mathrm{c}$ of the lineal trend variable showed structural breaks in both cases of prices in normal values and in natural log.

${ }^{10}$ The calculation for Table 2.3 is as follows: First, calculate $[y(t)-\operatorname{trend}(t)] / \operatorname{trend}(t) ; t$ is defined as 1 year. This is the value of the deviation from trend, which is then expressed as percentage of the trend. Second, take the absolute value of that percentage for every year. Third, calculate the average for the decade. Conceptually, this is similar to the coefficient of variation calculated as the standard deviation of a variable divided by the average of that variable over a certain period.
} 
Table 2.3 Different indicators of volatility

\begin{tabular}{l|r|r|l|l}
\hline Volatility & \multicolumn{1}{|c|}{ HP } & \multicolumn{1}{c|}{ CF } & LT & $\begin{array}{l}\text { StDev of LN } \\
\text { prices }\end{array}$ \\
\hline $1960 \mathrm{~s}$ & 5.1 & 6.1 & 20.6 & 3.4 \\
\hline $1970 \mathrm{~s}$ & 17.2 & 13.8 & 31.1 & 21.3 \\
\hline $1980 \mathrm{~s}$ & 5.1 & 4.5 & 20.4 & 6.7 \\
\hline $1990 \mathrm{~s}$ & 7.4 & 4.3 & 9.6 & 7.2 \\
\hline $2000 \mathrm{~s}$ & 8.7 & 5.2 & 20.8 & 9.9 \\
\hline $2010 \mathrm{~s}$ & 5.6 & 3.8 & 22.4 & 10.2 \\
\hline
\end{tabular}

Source: Author calculations based on data from the International Monetary Fund (IMF)

without the trend that is shown in Tables 2.1 and 2.2 (called "StDev of LN prices" here).

First, using a fixed trend for the whole period (LT) leads to higher estimates of volatility (a log-linear trend would produce qualitatively similar results). Second, all of the measures of volatility indicate higher volatility in the 1970s. However, to the extent that the HP and CF filters allow for the extraction of trends, the implied volatility around those trends is lower than those in the case of "StDev of LN prices." This last measure basically uses a different lineal trend for every decade (the average for the period), which although it avoids the problem of the LT of applying the same lineal trend for several decades, will still not capture changes in trends occurring within a decade. Third, as an extension to the previous point, because food prices increased at a slower rate in the 2000s than in the 1970s, the HP filter and particularly the CF filter regard part of the total volatility calculated using "StDev of LN prices" as changes in trend.

In summary, it is important to keep in mind that for any kind of analysis of price series, assumptions about trend behavior and the corresponding detrending method will affect the conclusion about price variability. When using measures that ignore trends, changes in underlying trends (which is usually related to more permanent factors) may be wrongly characterized as changes in volatility. Also, policies that address changes in underlying trends are different from those used to confront changes in volatility.

\subsubsection{Shorter-term Variations}

Until now, the discussion has focused on trends and cycles. However, as already noted, there are different forms of volatility that are conflated in the measure that uses the standard deviation of inflation, the latter measured as the difference of prices in $\log$ s (which corresponds to StdDEV of LN prices in Table 2.3) (i.e., the

The main difference between the measure utilized in this chapter and the concept mentioned in the previous sentence is that in the latter, the trend is assumed to be a flat lineal value for the period, while in Table 2.3, the trend may be changing during that period. 


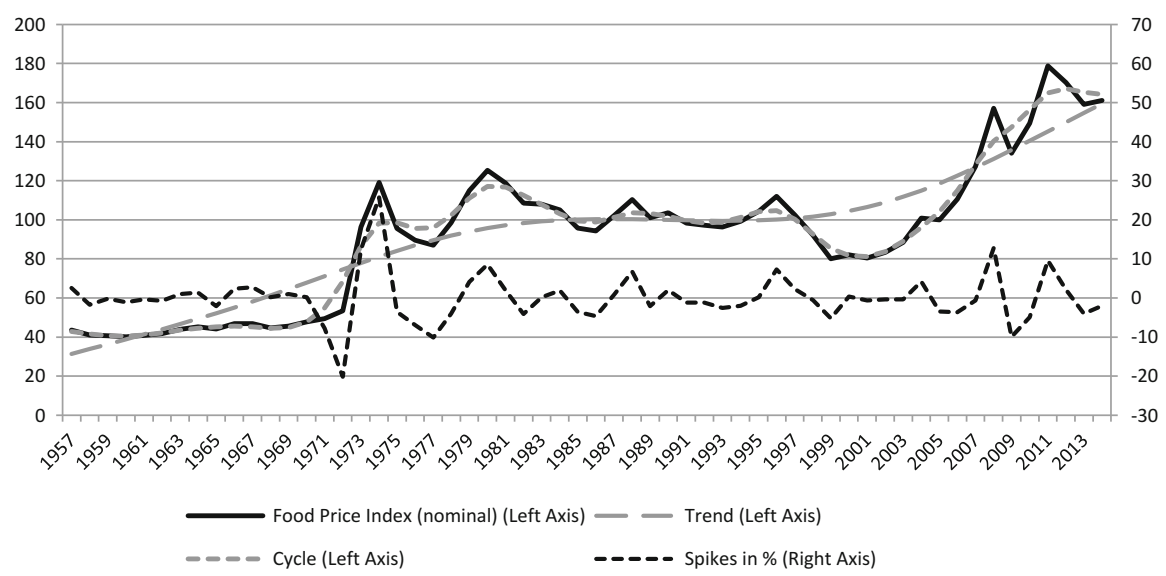

Fig. 2.9 Trends, cycles, and spikes. Source: Author calculations based on data from the International Monetary Fund (IMF)

difference of prices in logs). An increase in volatility measured this way may be due to (a) changes in the longer-term trend, (b) a medium-term cycle, and (c) shorterterm volatility, which in some cases may reach the level of extreme events. Points (a) and (b) have already been discussed in the previous sections. Identifying short-term volatility is also a topic relevant to policymaking, particularly if volatility reaches the level of an extreme event.

Understanding the causes of an extreme price event is essential for designing an appropriate policy to react to the event. To do that requires differentiating between the three elements of volatility mentioned above. For instance, the policy approach to changes in price trends (point a), linked to significant long-term modifications of underlying income growth and demographic trends, may be different from the policy approach to demand-side macroeconomic forces driving the business cycle (point b). Weather problems, sudden changes in trade policies of systemically important countries, and abrupt shifts in financial conditions (all of which would affect short-term volatility in prices) may require yet other policy approaches. However, as before, such decomposition of the three aspects (trends, cycles and shorter-term variations) faces the problem of how to differentiate them.

Figure 2.9 presents a possible decomposition using the HP filter (for another approach to the decomposition, see Tadesse et al. 2014).

The smoothness of the variable resulting from the HP filter can be modified using different values of the penalty parameter (let us call it lambda) in the HP optimization algorithm. Applying the HP to a variable, the larger the lambda value, the smoother the series is; if lambda approaches infinity, the series is a lineal trend. Here, the lambda value of 100 is used for calculating the trend and 6.25 for the cycle (see Ravn and Uhlig 2002 for a discussion of how to adjust the HP filter). Then short-term volatility is the difference between the actual price $p_{t}$ and the value 
of the HP filter at $t$ representing the business cycle level expressed as a percentage of the value of the HP filter which, in turn, stands for the trend level.

In the 1970s, the breakdown of the Bretton Woods system of exchange rates and a series of supply and demand shocks led to a steep upward adjustment in nominal food prices and other commodities. From then until the mid-2000s, nominal food prices were oscillating around that new plateau, in part affected by the global business cycle (as already discussed). The nominal prices bottomed out between the late 1990s and early 2000s, a period in which price declines were deeper and more extended than the previous lows. This was the result of a series of financial crises-starting with the 1997 Asian financial crisis and ending with the 2002 Argentine crisis - which reduced demand and/or increased supply of food (and commodity) products. The early 2000s saw the decline in global growth and the last cycle of the US dollar peaking (see the discussion about the macro factors in the 1970s and the 2000s in Díaz-Bonilla 2008, 2015). However, until about 2005, the nominal increase was in line with previous nominal cycles.

In the second part of the 2000s, there are at least two events to consider: first, the trend was moving upward since hitting a nominal bottom in the late 1990s and early 2000s and second, the price spikes occurred in 2008 and 2011. As discussed in another study (see Díaz-Bonilla 2010), the peak of the 2008 spike was smaller, and reaching it took place over a longer period of time, when compared with the spike in the early 1970s. In the 1970s, there was an almost $200 \%$ increase in the index of nominal food prices in about 5 years, while in the 2000s, the increase was less than $140 \%$ over almost 9 years. If extreme high price events are defined as those being more than two standard deviations from the average, only the price spikes in 1974 and 2008 can be considered as an extreme price event (the 2011 shock was less than two SD from the average). Figure 2.9 also shows the smaller food price spikes in the late 1970s (related to the second oil shock) and in the second half of the 1980s and mid-1990s (more related to weather events) (see a discussion in Díaz-Bonilla 2010).

This book analyzes different reasons for the more recent price spikes in 2008 and 2011. The decomposition discussed in this chapter points to a component of that volatility: the potential change in the medium-term trends of nominal and real prices. Having reached another plateau in the 2010s, food prices in nominal terms may remain at that level (with likely fluctuations similar to those seen as prices reached the plateau in the 1970s). However, if nominal prices stay at the new plateau with oscillations, prices in real terms will decline. This would imply a reversion of the small upward trend shown in Fig. 2.1, probably returning to the long-term decline in real terms since the 1980s (a discussion of scenarios is in Díaz-Bonilla et al 2014; Díaz-Bonilla 2015). The analysis of changes in these medium- to longerterm events requires the variability of trends to be disentangled from the cyclical and temporary components of overall price volatility. 


\subsubsection{Expected and Historical Volatility}

All the measures of volatility discussed so far have been based on historical data, which are the actual realization of the variables of interest. However, economic agents base their decisions on the expected value of the relevant variables, in this case food prices (Torero 2012). That expected values may follow some backwardlooking and adaptive rules of thumb or be based on more sophisticated modeling of future scenarios. In the case of commodities with future markets, volatility can be calculated using future prices. However, only in the case of perfect foresight would ex post realized values of prices and their volatility coincide with ex ante expected values.

Furthermore, in this line of analysis, it can be argued that "true" volatility (the expected volatility) in the context of economic decisions is only the difference between the expected price at time $t+1$ that is forecasted at time $t$ and the realized price at time $t$. On the other hand, the difference between the expected price at time $t+1$ that is forecasted at time $t$ and the realized price at time $t+1$ is the unexpected volatility, which by definition is not included in a farmer's economic decision-making. In turn, these two measures are different from the calculations based on the realized price difference between $t$ and $t+1$. Therefore, according to this view, the expected prices should be first estimated when calculating volatility. This opens the broader issue of how expectations are formed and modeled, which will not be discussed here (see, for instance, Triantafyllou et al. 2013).

\subsubsection{Scaling the Shocks}

The previous sections about trends and volatility have not yet discussed the impact of price changes on countries, producers, and consumers. Analyzing this impact requires not only trends and volatility to be properly characterized but also the relevant shocks to be properly scaled by macroeconomic variables, such as GDP, exports or fiscal accounts (at country level), and household income or consumption (at producer and consumer levels). An example of such scaling at country level is a series of studies conducted by Bela Balassa in the early 1980s to analyze different global economic shocks in the 1970s, including the price events during that period (see, for instance, Balassa 1984, 1986).

In the case of food prices, a possible indicator of the size of a price shock at country level may be obtained by dividing food imports by total exports (i.e., how much of the income from all exports a country needs to pay for the food import bill). This seems to be a better proxy for affordability and the potential burden on the balance of payment at national level than other indicators, such as the net food trade position (Díaz-Bonilla et al. 2000). ${ }^{11}$ Figure 2.10 presents this indicator evaluated

\footnotetext{
${ }^{11}$ Like any other indicators, this indicator has its limitations. First, it reflects not only food prices but also other price and income effects on food imports and total exports. Also, in theory, if
} 


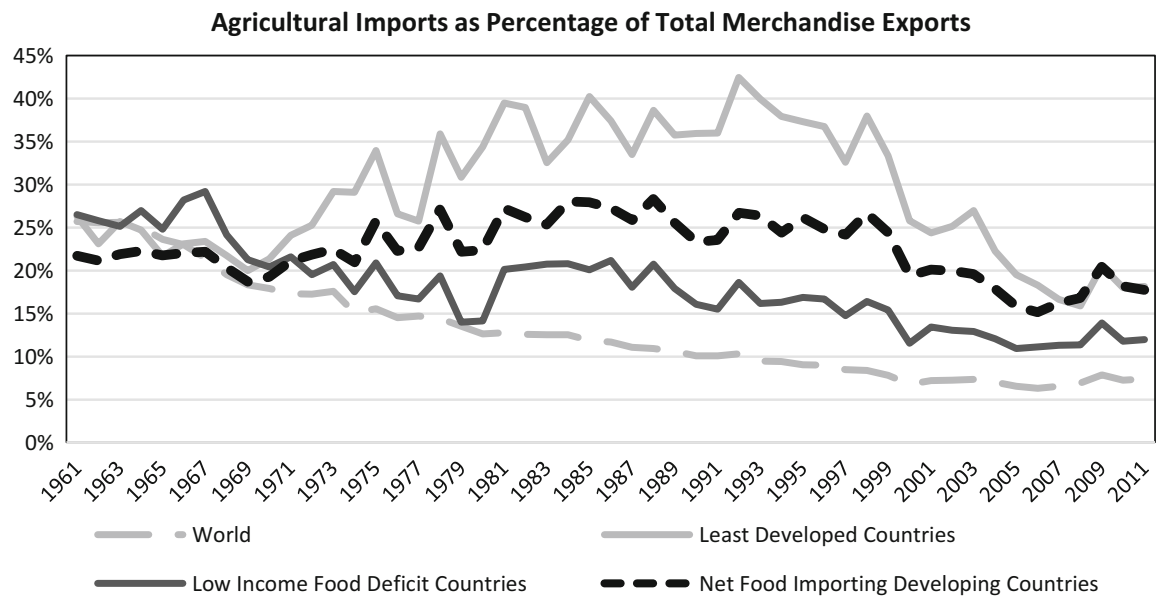

Fig. 2.10 Agricultural imports as percentage of total exports. Source: Author calculations based on data from FAOSTAT

with data on agricultural products (a broader category than food products alone) of several aggregates of countries: least developed countries (as defined by the UN), net food importing countries (as defined by the WTO, with some implications on trade negotiations), and low-income food-deficit countries (a category defined by the FAO).

The price shock in the 1970 s clearly affected those groups of countries more than the 2008 price shock (at the time of this writing, data for 2012 was still unavailable; therefore, the effects of the 2011 shock cannot be evaluated). Of course, this indicator should also be calculated at country level and not only for the aggregates of countries.

\subsection{Conclusions}

This paper has argued that the analysis of volatility may benefit from differentiating between trends, cycles, and shorter-term events. And if so, it is important to clarify

quantities of food imports decline significantly because of high international prices, the indicator may not change at all, but domestic prices and welfare would still be affected. It should, however, be noted that food items are usually relatively price inelastic. Furthermore, at the level of aggregation of total food imports, results are even more muted because of substitution effects across different items. For instance, in the case of LDCs as a whole, quantities of food imports declined by $1.3 \%$ in 2008 when compared with 2006, while world food prices increased by about $33 \%$ during the same period, according to the IMF index. This translates into an uncompensated point elasticity of about -0.04 between those years. Finally, it should be noted that the ratio in Fig. 2.10 is not used as a welfare indicator, but it is a proxy for the economic burden of high food prices at the BOP level. 
how trends are defined and measured and whether shocks can fall outside a "normal range" (which also requires "normal" to be defined). Different approaches to tackle those issues were discussed.

Regardless of whether price data are decomposed into trends, cycles, and shorterterm events, there are also various data issues to consider when analyzing volatility, for instance, (a) whether it corresponds to those of world markets or domestic markets; (b) if the focus is on world prices, it is necessary to define the currency of quoted prices (such as the US dollars, euros, SDRs, and so on); and (c) if a volatility analysis is centered on domestic prices, then the markets relevant to price formation and measurement must be identified along the value chain (production, processing, and distribution) that link primary producers to final consumers. It is also important to clarify whether volatility is analyzed using nominal prices or real prices; in the case of the latter, an appropriate deflator must be identified (such as the EUV index for advanced economies, the US CPI, or other nominal indices). In addition, it is crucial to identify whether the analysis focuses on specific commodities or broader aggregates of commodities. Finally, it is necessary to explicitly define the time period when determining volatility. Whether the time period is annual, seasonal, monthly, or even daily depends on the purpose of the analysis. For instance, if the analysis focuses on consumers, the time period (monthly) may be shorter than when the analysis focuses on producers. This is because producers make decisions based on longer time frames (at least yearly for planting decisions of many crops and even longer for investment decisions).

Irrespective of the way volatility is defined and measured, identifying its impact on nations, producers, and consumers requires (a) proper scaling of changes in prices; (b) taking a systemic view of trends, cycles, shocks, and crises; and (c) considering all macroeconomic cross effects (fiscal, monetary, inflation, exchange rates) of increases in all commodity prices (not only food) and other world variables (such as in Balassa 1984, 1986).

The price shocks in 2008 and 2011 focused the attention of the public and policymakers on price volatility. However, the results obtained from decomposing data into trends, cycles, and shorter-term volatility also suggest that there is a need to determine whether price variations respond to cyclical and shorter-term movements or whether they rather result from a changing trend reflecting adjustments in longterm fundamentals that need to be properly understood.

Open Access This chapter is distributed under the terms of the Creative Commons AttributionNoncommercial 2.5 License (http://creativecommons.org/licenses/by-nc/2.5/) which permits any noncommercial use, distribution, and reproduction in any medium, provided the original author(s) and source are credited.

The images or other third party material in this chapter are included in the work's Creative Commons license, unless indicated otherwise in the credit line; if such material is not included in the work's Creative Commons license and the respective action is not permitted by statutory regulation, users will need to obtain permission from the license holder to duplicate, adapt or reproduce the material. 


\section{References}

Aguiar M, Gopinath G (2004) Emerging market business cycles: the cycle is the trend. NBER Working Paper 10734. National Bureau of Economic Research, Cambridge, MA

Allcott H, Lederman D, López R (2006) Political institutions, inequality, and agricultural growth: the public expenditure connection. World Bank, Washington, DC

Arimond M, Ruel M (2006) Dietary diversity is associated with child nutritional status: evidence from 11 demographic and health surveys. J Nutr 134:2579-2585

Balassa B (1984) Adjustment policies in developing countries: a reassessment. World Dev 12(9):955-972

Balassa B (1986) Policy responses to external shocks in developing countries. Am Econ Rev 76(2):75-78

Barrett C, Bellemare M (2011) The G-20's error: food price volatility is not the problem. Cornell University Press, Ithaca, NY

Blanchard O, Dell'Ariccia G, Mauro P (2010) Rethinking macroeconomic policy. IMF Staff Position Note 10/03. Washington, DC

Canova F (1998) Detrending and business cycle facts. J Monet Econ 41:475-540

Canova F (1999) Does detrending matter for the determination of the reference cycle and the selection of turning points? Econ J 109(452):126-150

Canova F (2007) Methods for applied macroeconomic research. Princeton University Press, Princeton, NJ

Christiaensen L, Demery L, Kuhl J (2010) The (evolving) role of agriculture in poverty reduction. United Nations University, World Institute for Development Economics Research Working Paper 2010/36. Helsinki

Diaz-Bonilla E (2008) Global macroeconomic developments and poverty. In: IFPRI Discussion Paper No. 00766. Markets, Trade and Institutions Division. Available at http://ageconsearch. umn.edu/bitstream/42324/2/ifpridp00766.pdf

Díaz-Bonilla E (2010) Globalisation of agriculture and food crises: then and now. In: Karapinar B, Häberli C (eds) Food crises and the WTO. Cambridge University Press, Cambridge, UK

Díaz-Bonilla E (2014) On food security stocks, peace clauses, and permanent solutions after Bali. IFPRI Working Paper. Washington, DC

Díaz-Bonilla E (2015) Macroeconomics, agriculture, and food security: an introductory guide for policy analysis in developing countries. IFPRI Books, Washington, DC

Díaz-Bonilla E, Ron J (2010) Food security, price volatility and trade: some reflections for developing countries. ICTSD Programme on Agricultural Trade and Sustainable Development Issue Paper 28. International Center for Trade and Sustainable Development, Geneva

Díaz-Bonilla E, Thomas M, Robinson S, Cattaneo A (2000) Food security and trade negotiations in the world trade organization: a cluster analysis of country groups. IFPRI Discussion Paper 59. Washington, DC

Díaz-Bonilla E, Saini E, Creamer B, Henry G, Trigo E (2014) Global strategic trends and agriculture, and R\&D in Latin America and the Caribbean. A framework for analysis. CIAT, Cali

Dorosh P, Robinson S, Ahmed H (2009) Economic implications of foreign exchange rationing in Ethiopia. ESSP2 Discussion Paper 009. Ethiopia Strategy Support Program 2 (ESSP2). Development Strategy and Governance Division, International Food Policy Research Institute, Ethiopia Strategy Support Program 2, Addis Ababa, Dec 2009

Eastwood R, Lipton M (2000) Pro-poor growth and pro-growth poverty reduction: meaning, evidence, and policy implications. Asian Dev Rev 18(2):22-58

Fan S (ed) (2008) Public expenditures, growth, and poverty: lessons from developing countries. Johns Hopkins University Press, Baltimore

Food and Agriculture Organization of the United Nations (FAO) (2014) FAOSTAT. FAO database. Available at http://faostat3.fao.org/home/E 
G20 (2010) Price volatility in food and agricultural markets: policy responses. Policy report including contributions by FAO, IFAD, IMF,OECD, UNCTAD, WFP, the World Bank, the WTO, IFPRI and the UN HLTF, 2 Jun 2011

Gilbert CL, Wyn Morgan C (2010) Has food price volatility risen? Working Paper 2/2010, University of Trento, Department of Economics, 8 Apr 2010

Haggblade S, Hazell P (2010) Successes in African agriculture: lessons for the future. IFPRI Issue Brief 63. Washington, DC

Haggblade S, Hazell P, Reardon T (eds) (2007) Transforming the rural non-farm economy. Johns Hopkins University Press, Baltimore

Hazell P, Shields G, Shields D (2005) The nature and extent of domestic sources of food price instability and risk. In: Paper presented to the international workshop on managing food price instability in low-income countries, Washington, DC, 28 Feb-1 Mar

Headey D (2014) Food prices and poverty reduction in the long run. IFPRI Discussion Paper 01331. Poverty, Health, and Nutrition Division, Washington, DC

Ivanic M, Martin W (2014) Short- and long-run impacts of food price changes on poverty. Policy Research Working Paper 7011. Development Research Group, Agriculture and Rural Development Team. World Bank, Washington, DC

Mogues T, Yu B, Fan S, McBride L (2012) The impacts of public investment in and for agriculture: synthesis of the existing evidence. IFPRI Discussion Paper 01217. Washington, DC

Mundell R (2002) Commodity prices, exchange rates and the international monetary system. In: Presentation by Robert Mundell at the Consultation on Agricultural Commodity Price Problems, Commodities and Trade Division, Food and Agriculture Organization of the United Nations. Rome, 25-26 Mar. Available at www.fao.org/docrep/006/Y4344E/y4344e04.htm

Rashid S, Lemma S (2011) Strategic grain reserves in Ethiopia: institutional design and operational performance. IFPRI Discussion Paper 01054. Washington, DC

Ravn MO, Uhlig H (2002) On adjusting the Hodrick-Prescott filter for the frequency of observations. Rev Econ Stat 84:371-375

Rotemberg JJ, Woodford M (1999) The cyclical behavior of prices and costs. Handb Macroecon 1:1051-1135

Stock JS, Watson M (1988) Variable trends in economic time series. J Econ Perspect 2(3):147-174

Tadesse G, Algieri B, Kalkuhl M, von Braun J (2014) Drivers and triggers of international food price spikes and volatility. Food Policy 47:117-128

Timmer P (1989) Food price policy: the rationale for government intervention. Food Policy 14(1):17-27

Timmer CP, Falcon WP, Pearson SR (1983) Food policy analysis. Johns Hopkins University Press, Baltimore

Torero M (2012) Food prices: riding the rollercoaster. Chapter 2 in 2011 Global Food Policy Report. International Food Policy Research Institute (IFPRI), Washington DC

Triantafyllou A, Dotsis G, Sarris A (2013) Volatility forecasting in agricultural commodity markets. Available at http://www.aueb.gr/conferences/Crete2014/papers/Triantafyllou.pdf

World Bank (2005) Managing food price risks and instability in an environment of market liberalization. Agriculture and Rural Development Department Report 32727-GLB. Washington, DC

World Bank (2014) World development indicators. Available at http://data.worldbank.org/datacatalog/world-development-indicators 